\title{
The Effect of Plant Density on Growth and Yield of Inbred Lines and Hybrids of Corn (Zea mays L.)
}

\author{
Abd - AlKream Hussain Al-Romi ${ }^{\mathrm{a}} \quad$ Abduallh Fadhal Sarheed $^{\mathrm{b}} \quad$ Rasha Adel Abd Al-Nabi $^{\mathrm{c}}$

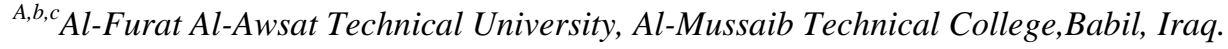

Abdfadel68@yahoo.com

Submission date:- 23/11/2017 Acceptance date:- 11/4/2018 Publication date:- 11/11/2018

Keywords: lines, diallel hybrid, genotype

\begin{abstract}
A Filed experiment was carried out at the center of the guiding and training agriculture AL-Mahnawia - Babylon during spring season 2015 and autumn season at the same year growing six lines (OH40،ZP707،ZP670،IK8،R153 and Dk)to study and evaluation these lines and its hybrids at autum season 2015 for traits : leaf area ,number of ears ,number of grain .ears ${ }^{-1}$, grain yield ,total grain yield, by plating at $(20,25,30) \mathrm{cm}$.by using RCBD design for three replicates.
\end{abstract}

The results showed that significant difference among the genotypes ,plant density and the interaction among them . The fifth inbred was superior for all study traits leaf area, number of ears, number of grains.ear ${ }^{-1}$, grain yield ,total grain yield it gives $3466 \mathrm{~cm}^{2}, 1.10$ ear.plant ${ }^{-1} .393 .36$ grans ear ${ }^{-1}, 125.45$. gr, plant ${ }^{-1}, 10.6$ ton.ha ${ }^{-1}$ at $25 \mathrm{~cm}$ it was superior on all the study inbreds by giving high value of these traits .on other hand the hybrid (R153× IK8 )gave high range of all study traits $5439 \mathrm{~cm}^{2}, 1.25$ aer.plant ${ }^{-1} .635 .30$ gr. Plant ${ }^{-1} 10.6$ ton. ha ${ }^{-1}$. The line R153 and the hybrid( R153× IK8) gave best interaction.

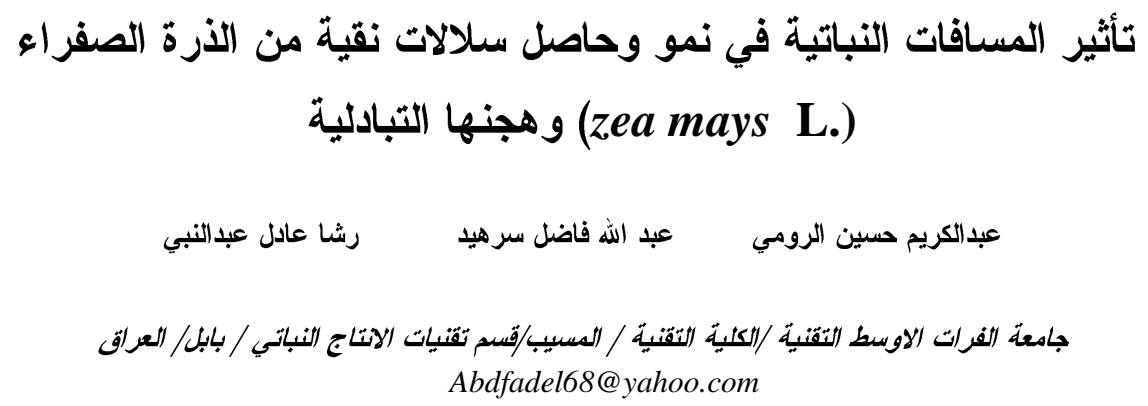

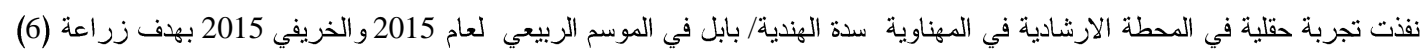

سلالات نقية من الذرة الصفراء (DK R153،IK8،ZP670،ZP707،OH40) في الموسم الربيعي وتهجينها وفي الموسم الخريفي تقييم

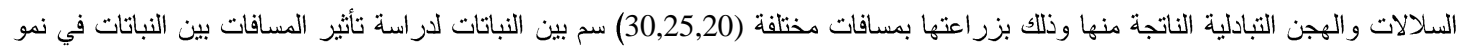

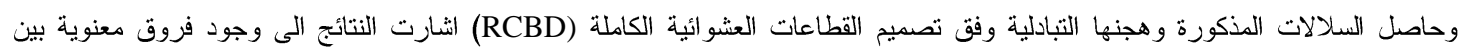

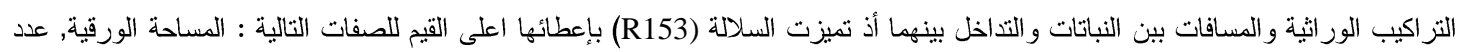

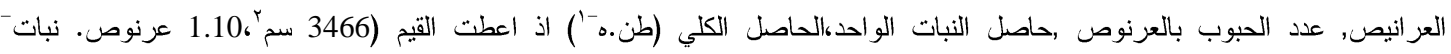

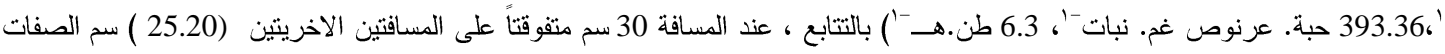

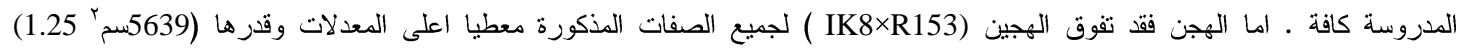

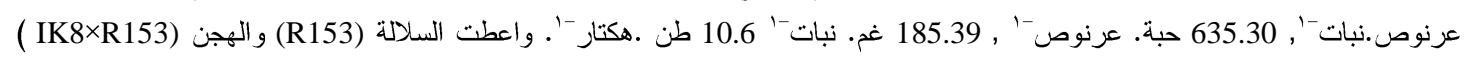
عند المسافة (25) سم افضل تداخل بينهما. 
تعد الذرة الصفر اء من المحاصيل ذات الاهمية الصناعية و الغذائية فهي تدخل في كثير من الصناعات منها استخر اج الزيت والنشأ وامكانية

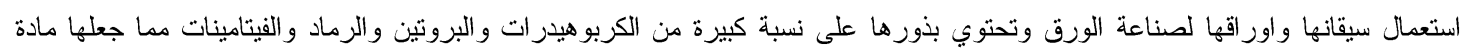

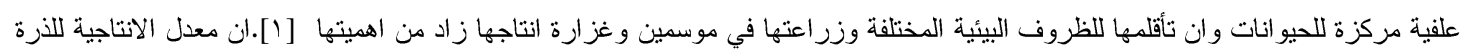

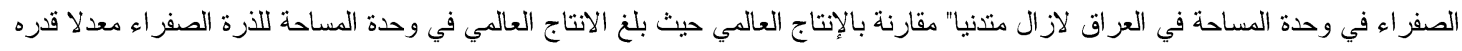

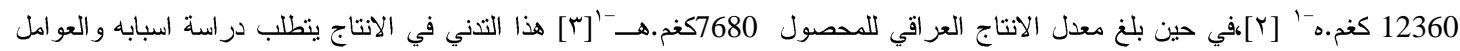

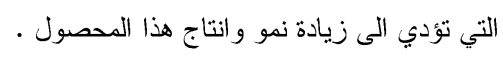

ان اسلوب توزيع النباتات في وحدة المساحة من اهم العوامل المؤثرة في انتاجية هذا المحصول اذ ان تحديد كمية الضوء المعتزض والنافذ

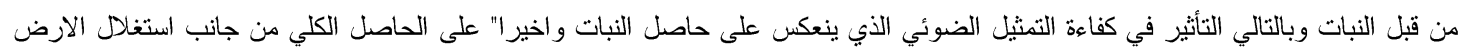

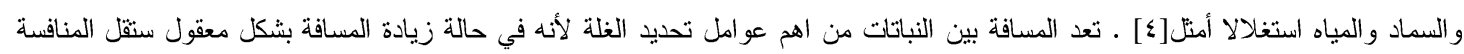

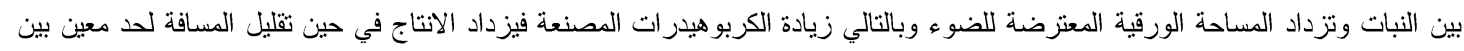

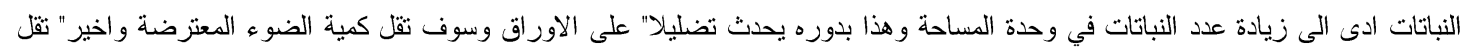

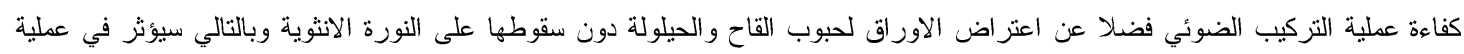

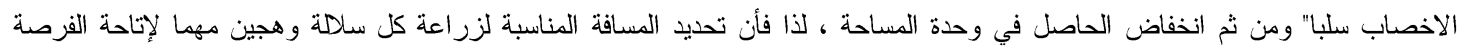

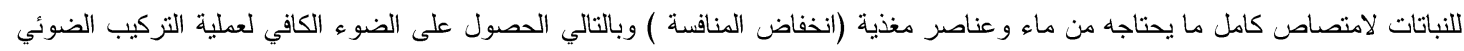

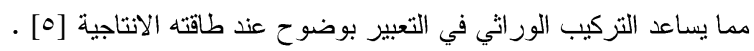

اثثرت المسافات بين النباتات لمحصول الذرة الصفراء على حاصل النبات ووزن الحبوب في العرنوص و عدد الحبوب في العرنوص وزيادة

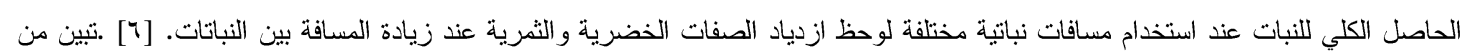

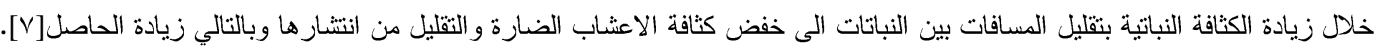

$$
\text { وتهدف الدراسة الى: }
$$

() اختيار السلالات النقية المميزة التي تعد القاعدة الور اثثة الاساسية لإنتاج الهجن الفردية ذات قوة الهجين العالية.

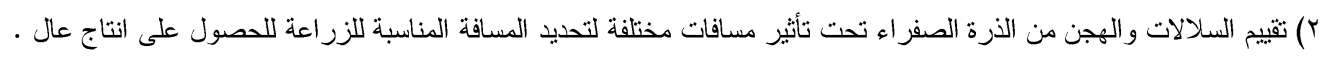

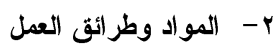

نفذت تجربة حقلية في محطة المهناوية الارشادية / بابل للموسم الربيعي 2015 بهدف تهجين (6) سلالات من الذرة الصفراء تم الحصول عليها من مديرية البحوث الزراعية / ابوغريب تهجينا نصف نتادلي اما الموسم الخريفي 2015 فتم تقييم السلالات والهجن الناتجة منها تحت

جدول (1) رموز السلالات النقية للارة الصفراء ومنشئها ومصادر الحصول عليها

\begin{tabular}{|c|c|c|c|}
\hline جهة الحصول عليها & المنشأ & رمز السلالة & ت \\
\hline مديرية البحوث الزر اعية / بغداد & ايطاليا & $\mathrm{OH} 40$ & 1 \\
\hline$=$ & $=$ & ZP707 & 2 \\
\hline$=$ & $=$ & ZP670 & 3 \\
\hline$=$ & هنكاريا & IK8 & 4 \\
\hline$=$ & 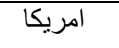 & R153 & 5 \\
\hline$=$ & 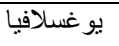 & DK & 6 \\
\hline
\end{tabular}


r- الموسم الربيعي لعام 2015

اعدت ارض التجربة من حراثة متعامدة وتتعيم وتسوية و تمريز وتم اضافة السماد الفوسفاتي

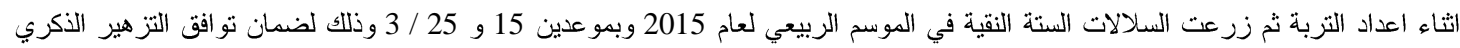

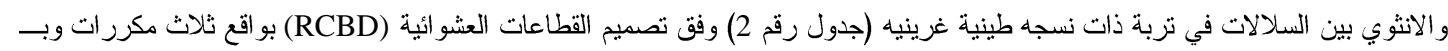

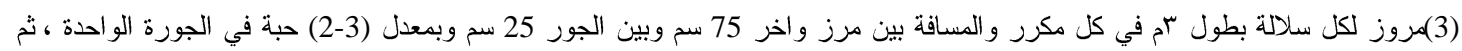

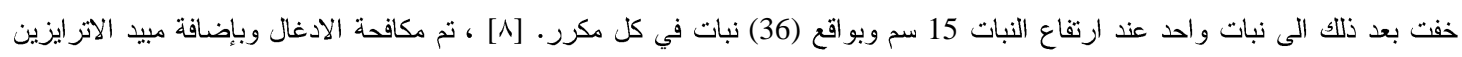

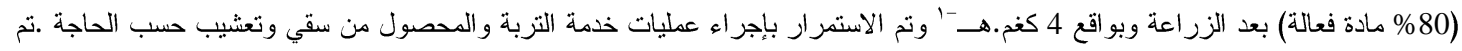

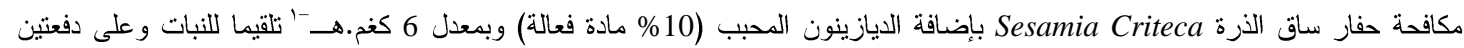

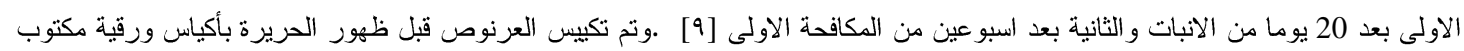

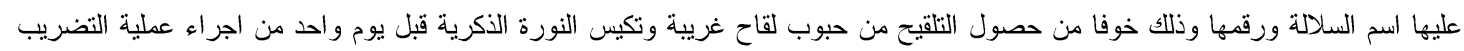
وذللك لمنع اختلاط حبوب لقاح التركيب الوراثي من تركيب وراثي اخر وكذللك تضمن موت حبوب التقاح القديمة وتجمع حبوب اللقاح في اليوم

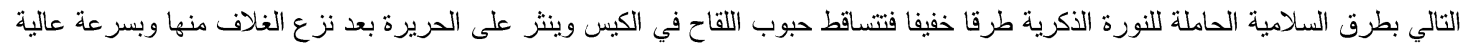

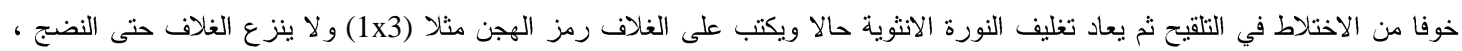

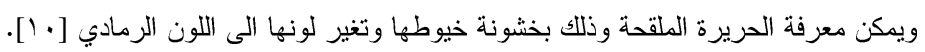

؛ - الموسم الخريفي لعام 2015

زرعت بذور السلالات النقية وهجنها التبادلية الناتجة من التلقيح نصف التبادلي للموسم السابق بتاريخ 20/7/2015 وفقا لتصميم القطاعات العشو ائية الكاملة مCBD وبو اقع (r-r) حبه للجوزة الو احدة وخفت الى نبات واحد وبو اقع اربعة مروز لكل تركيب وراثي وبطول 4 م وبثلاثة

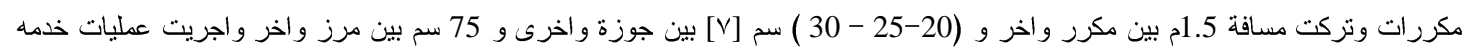

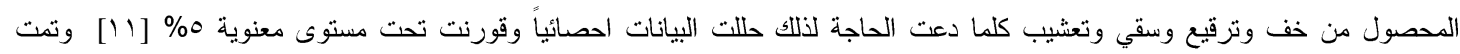
دراسة الصفات الاتية للسلالات والهجن نصف وسفي ونتئن التبادلية :

$$
\begin{aligned}
& \text { 1- المساحة الورقية (سم) }
\end{aligned}
$$

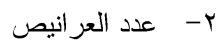

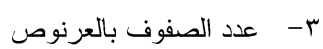

$$
\begin{aligned}
& \text { ع- حاصل النبات الو احد (غم. نبات -) } \\
& \text { ه- - الحاصل الكلي (طن ـ هـ-') }
\end{aligned}
$$

\begin{tabular}{|c|c|c|}
\hline نتيجة التحليل & وحدة القياس & نوع التحليل \\
\hline 62 & $\%$ & غرين \\
\hline 13 & $\%$ & رمل \\
\hline 25 & $\%$ & طين \\
\hline طينية غرينية & - & نسجة التربة \\
\hline 7.2 & - & درجة التفاعل PH \\
\hline 4.5 & ديسميز . م21-2 & التوصبل الكهربائي EC \\
\hline 32.02 & PPM & الفسفور الجاهز \\
\hline 11.91 & PPM & النتروجين الجاهز \\
\hline 88.80 & PPM & البوتاسيوم الجاهز \\
\hline 6.6 & $\%$ & المادة العضوية \\
\hline
\end{tabular}

جدول (2) التحليل الكيميائي والفيزيائي لتربة التجربة

•-النتائج و المناقشة

يتضح من الجدول (3) وجود فروقات معنوية بين النراكيب الور اثنية لصفة المساحة الورقية اذ تفوقت السلالات (5) بإعطائها اعلى مساحة

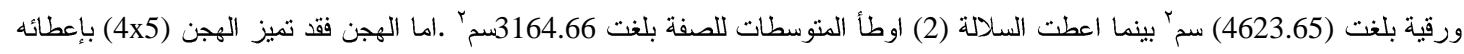

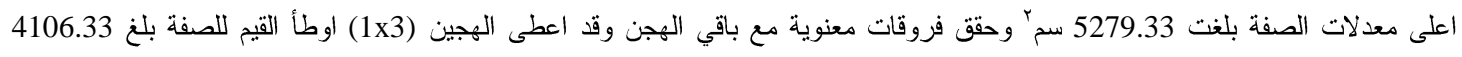


اما المسافات بين النباتات فكان معنويا للصفة فقد تميزت المسافة (30) سم على بقية المسافات بإعطائها اعلى معدل للصفة بلغ 4651.52

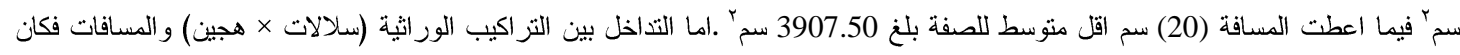

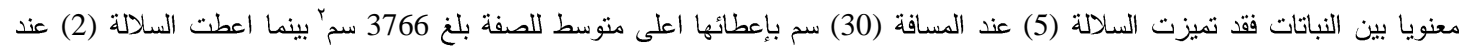

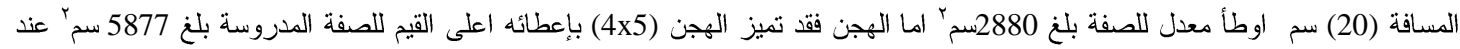

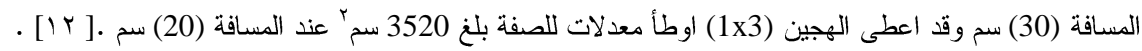

ويعود السبب في ارتفاع و انخفاض متوسط المساحة الورقية الى اختلاف التراكيب الور اثثية والمسافة بين النباتات وتعد عاملا مهما لقلة

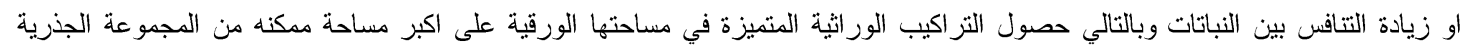
وبالتالي حصولها على الكمية الكافية من الماء والعناصر الغذائية وهذا مما يؤثز على النمو الخضري ولانية سيما المساحة الورقية وزيادة كفاءة

عملية التركيب الضوئي.

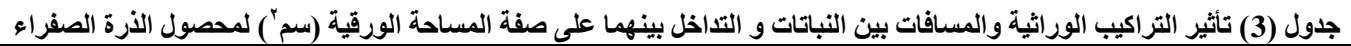

\begin{tabular}{|c|c|c|c|c|}
\hline \multirow[t]{2}{*}{ متوسط التراكيب الوراثية } & \multicolumn{3}{|c|}{ المسافات النباتية } & \multirow[t]{2}{*}{ التركيب الوراثي } \\
\hline & 30 & 25 & 20 & \\
\hline 3451.66 & 3645 & 3510 & 3200 & 1 \\
\hline 3164.66 & 3433 & 3181 & 2880 & 2 \\
\hline 3500.66 & 3688 & 3584 & 3230 & 3 \\
\hline 3279 & 3477 & 3350 & 3010 & 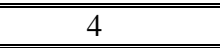 \\
\hline 3623.65 & 3766 & 3655 & 3450 & 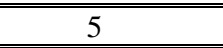 \\
\hline 3403.66 & 3551 & 3480 & 3180 & 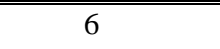 \\
\hline 3403.88 & 3593.33 & 3460 & 3158.33 & متوسط السلالات \\
\hline $\begin{array}{l}4764 \\
\end{array}$ & 5123 & 4792 & 44377 & $1 \times 2$ \\
\hline 406.33 & 4627 & 4172 & 3520 & $1 \times 3$ \\
\hline 44384 & 4785 & 4337 & 4030 & $1 \times 4$ \\
\hline 4809.66 & 5166 & 4873 & 4390 & $1 \times 5$ \\
\hline 44779 & 5120 & 4626 & 4291 & $1 \times 6$ \\
\hline $\begin{array}{l}4437 \\
\end{array}$ & 4831 & 4385 & 4095 & $2 \times 3$ \\
\hline 4520.66 & 4960 & 44992 & 4110 & $2 \times 4$ \\
\hline 48877 & 5270 & 49931 & 4430 & $2 \times 5$ \\
\hline 4561.33 & 5019 & 4533 & 4132 & $2 \times 6$ \\
\hline "4616.66 & 5111 & 4552 & 4187 & $3 \times 4$ \\
\hline 5091 & $\begin{array}{l}5486 \\
\end{array}$ & 5192 & $\begin{array}{l}4595 \\
\end{array}$ & $3 \times 5$ \\
\hline 4331 & 4722 & 4287 & 3984 & $3 \times 6$ \\
\hline 5279.33 & 5877 & 5272 & 4689 & $4 \times 5$ \\
\hline 4232 & 46665 & 4239 & 3792 & $4 \times 6$ \\
\hline 4963 & 5320 & 5083 & 44486 & $5 \times 6$ \\
\hline 4289.92 & \begin{tabular}{l|r} 
& 4651.52 \\
\end{tabular} & 4310.76 & 3907.50 & المتوسط \\
\hline التداخل/151.10 & التز اكيب الور اثية / 113.02 & المسافات & & L.S.D \\
\hline
\end{tabular}

يتضح من الجدول (4) وجود فروقات معنوية بين التزاكيب الوراثية و المسافات بين النباتات و التداخل بينها لصفة عدد العر انيص اذ تفوقت

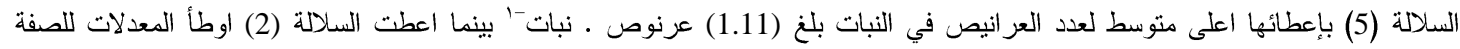

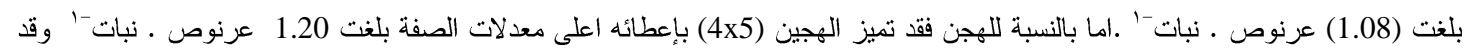

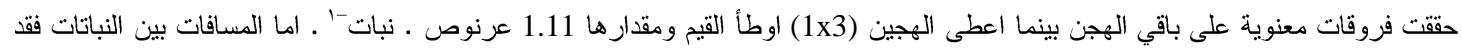

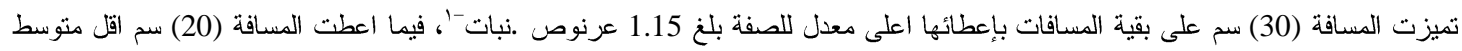

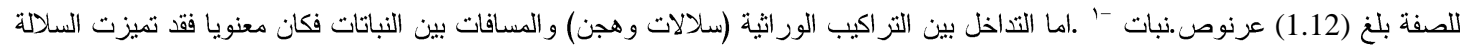

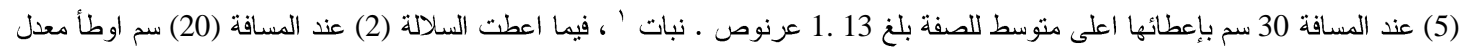

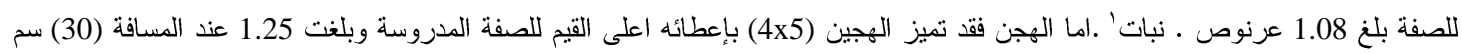

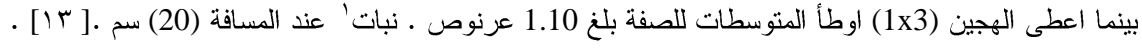

ويعود السبب الى ارتفاع وانخفاض معدل عدد العرانيص في النبات لاختلاف التراكيب الوراثية ومدى تفاعلها مع الظروف البيئية

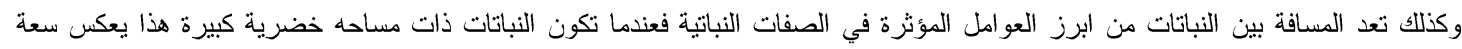

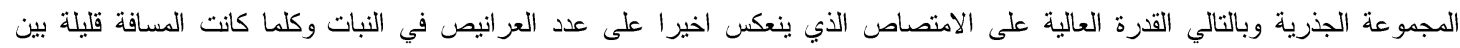

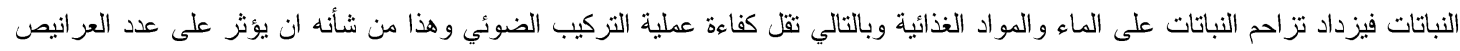


بالنبات كونه مكونا اساسيا من مكونات الحاصل ومن جهة اخرى ان امتصاص النبات للعناصر الغذائية بشكل عام والنتروجين بشكل خاص يؤدي

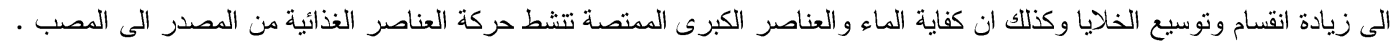

جدول (4) تأثير التراكيب الوراثية والمسافات بين النباتات و التداخل بينهما على صفة عدد العرانيص في النبات لمحصول الذرة الصفراء

\begin{tabular}{|c|c|c|c|c|}
\hline المتوسط & 30 سم & م & مسم & التر اكيب الور اثية \\
\hline 1.10 & 1.11 & 1.10 & 1.09 & 1 \\
\hline 1.08 & 1.09 & 1.08 & 1.08 & 2 \\
\hline 1.10 & 1.12 & 1.10 & 1.08 & 3 \\
\hline 1.09 & 1.10 & 1.09 & 1.07 & 4 \\
\hline 1.11 & 1.13 & 1.10 & 1.09 & 5 \\
\hline 1.09 & 1.11 & 1.09 & 1.08 & 6 \\
\hline 6.09 & 1.11 & 1.09 & 1.08 & متوسط السلالات \\
\hline 1.16 & 1.18 & 1.15 & 1.15 & $1 \times 2$ \\
\hline 1.11 & 1.12 & 1.12 & 1.10 & $1 \times 3$ \\
\hline 1.13 & 1.14 & 1.13 & 1.13 & $1 \times 4$ \\
\hline 1.16 & 1.19 & 1.16 & 1.15 & $1 \times 5$ \\
\hline 1.15 & 1.17 & 1.16 & 1.14 & $1 \times 6$ \\
\hline 1.13 & 1.14 & 1.14 & 1.12 & $2 \times 3$ \\
\hline 1.14 & 1.15 & 1.15 & 1.14 & $2 \times 4$ \\
\hline 1.17 & 1.19 & 1.17 & 1.16 & $2 \times 5$ \\
\hline 1.15 & 1.16 & 1.16 & 1.13 & $2 \times 6$ \\
\hline 1.15 & 1.17 & 1.15 & 1.13 & $3 \times 4$ \\
\hline 1.19 & 1.21 & 1.19 & 1.18 & $3 \times 5$ \\
\hline 1.12 & 1.13 & 1.12 & 1.12 & $3 \times 6$ \\
\hline 1.20 & 1.25 & 1.20 & 1.17 & $4 \times 5$ \\
\hline 1.11 & 1.13 & 1.11 & 1.11 & $4 \times 6$ \\
\hline 1.18 & 1.20 & 1.18 & 1.17 & $5 \times 6$ \\
\hline 1.14 & 1.56 & 1.14 & 1.21 & المتوسط \\
\hline \multicolumn{2}{|c|}{ للتداخل / 0.053} & \multicolumn{2}{|c|}{ التز اكيب الور اثية } & L.S.D \\
\hline
\end{tabular}

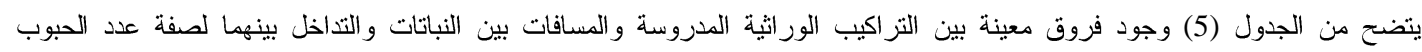

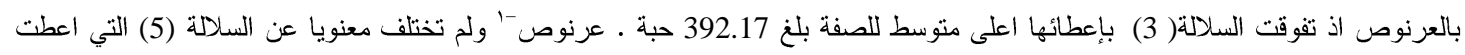

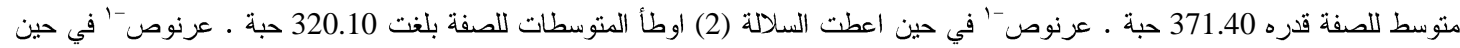

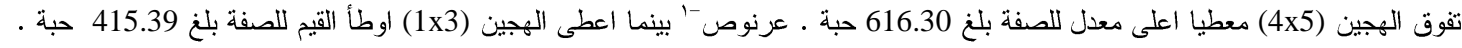
عرنوص - . .اما تأثير المسافات النباتية على صعفة عدد الحبوب بالعرنوص فكان معنويا فقد تميزت المسافة (30) سم على المسافتين الأخيرتين

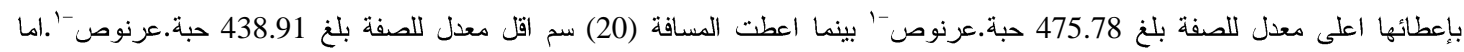

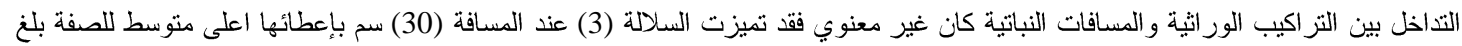

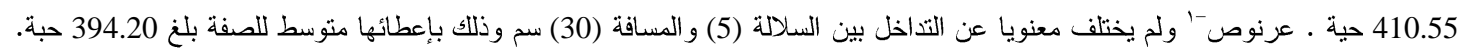
عرنوص-' بينما اعطت السلالة (2) عند المسافة (20) اوطأ المعدلات للصفة بلغت (4x5) عند المسافة (30) سم بإعطائه اعلى القيم للصفة المدروسة بلغت 632.42 حبة .عرنوص-' بينما اعطى الهجين (1x3) عند المسافة

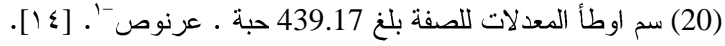

ويعود السبب في الارتفاع في صفة عدد الحبوب بالعرنوص الى سبيين اولهما قلة التتافس بين النباتات عند المسافة (30) سم ادى الى الى

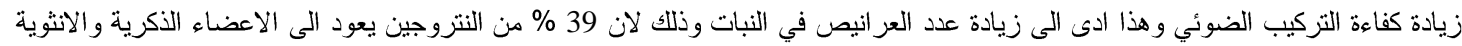

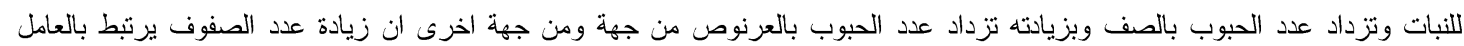
الور اثي ولكلا السلالتين المكونتين للهجين وكذلك لها علاقة قوية بقوة الهجين الحاصلة من تضريب السلالتين اضافة الى ان زيادة انقسام الخلايا في النورة الانثوية يزيد من عدد الحبوب بالصف ومن ثم يزداد عدد الحبوب بالعرنوص. 
جدول (5) تأثير التراكيب الوراثية والمسافات بين النباتات و التذاخل بينهما على صفة عدد الحبوب بالعرنوص للأرة الصفراء

\begin{tabular}{|c|c|c|c|c|}
\hline المتوسط & 30 سم & 25 25م & 20سم & التراكيب الوراثية \\
\hline 368.19 & 388.09 & 369.39 & 347.11 & 1 \\
\hline 320.10 & 345.59 & 333.60 & 281.10 & 2 \\
\hline 392.49 & 410.55 & 391.17 & 375.66 & 3 \\
\hline 331.33 & 345.43 & 332.66 & 317.71 & 4 \\
\hline 371.40 & 394.20 & 369.10 & 350.33 & $\overline{5}$ \\
\hline 362.6 & 379.54 & 367.10 & 336.15 & 6 \\
\hline 357.47 & 377.25 & 360.50 & 334.67 & متوسط السلالات \\
\hline 530.62 & 555.25 & 537.30 & 499.33 & $1 \times 2$ \\
\hline 419.67 & 439.17 & 422.39 & 397.47 & $1 \times 3$ \\
\hline 428.32 & 440.35 & $\begin{array}{l}433.70 \\
\end{array}$ & 4110.66 & $1 \times 4$ \\
\hline 532.36 & 550.64 & 528.71 & 519.10 & $1 \times 5$ \\
\hline 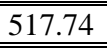 & 533.31 & 521.12 & 4998.81 & $1 \times 6$ \\
\hline 4449.40 & 462.12 & 451.73 & 434.35 & $2 \times 3$ \\
\hline 452.58 & 466.35 & 454.80 & 436.60 & $2 \times 4$ \\
\hline "563.55 & "585.10 & "564.30 & $\begin{array}{l}541.37 \\
\end{array}$ & $2 \times 5$ \\
\hline 463.85 & 480.66 & 468.10 & 442.81 & $2 \times 6$ \\
\hline 497.08 & (512.22 & 498.93 & 4881.10 & $3 \times 4$ \\
\hline "561.96 & $\begin{array}{l}578.71 \\
\end{array}$ & "565.58 & $\begin{array}{l}541.60 \\
\end{array}$ & $3 \times 5$ \\
\hline 435.40 & 451.73 & 4333.90 & 4220.59 & $3 \times 6$ \\
\hline 614.32 & 632.42 & 612.24 & 598.30 & $4 \times 5$ \\
\hline 420.13 & 430.18 & 422.38 & 407.83 & $4 \times 6$ \\
\hline 586.25 & 612.41 & $\begin{array}{l}575.44 \\
\end{array}$ & $\begin{array}{l}570.91 \\
\end{array}$ & $5 \times 6$ \\
\hline 457.96 & 475.78 & 459.21 & 438.91 & المتوسط \\
\hline \multicolumn{2}{|r|}{ للتز اكيب 40.31} & لل للمسافان & & L.S.D \\
\hline
\end{tabular}

ان صفة حاصل النبات صفة كمية وهي نتيجة لجميع التأثيرات الوراثية والبيئية لمكونات الحاصل وذات اثر بالغ لارتباطها بالناحية

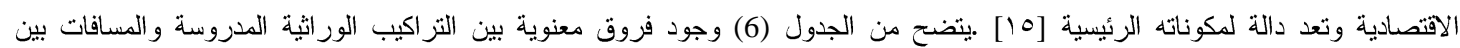

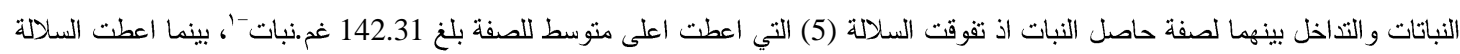

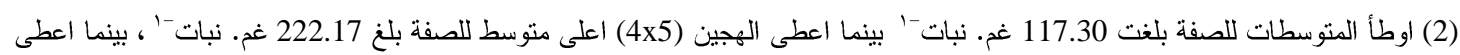

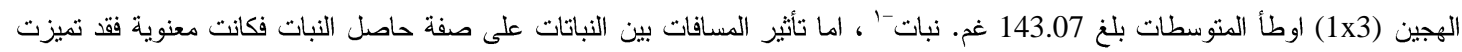

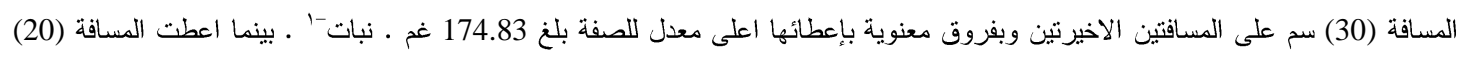

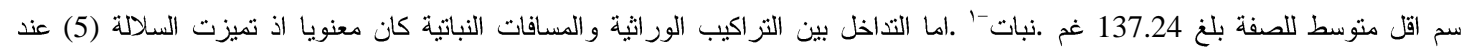

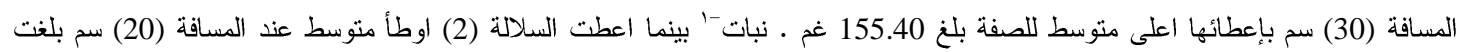
104.90 غم . نبات -1 .اما الهجين (4x5) فقد تفوق عند المسافة (30) سم معطيا اعلى متوسط للصفة المدروسة بلغت

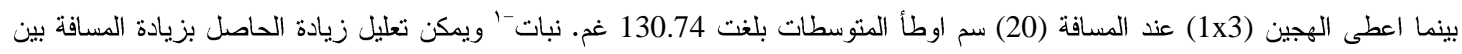
النباتات وذلك لأنه تزداد عدد الحبوب بالصف ولادين وعدد الصفوف بالعرنوص وعدد العرانيص للأسباب المذكورة في كل صفة والتي تزداد جميعها بزيادة المساحة الورقية وقلة التظليل للتراكيب الوراثية (اي قلة حبوب اللقاح الساقطة على الاوراق) وامتصاصها الكمية الكافية من الماء

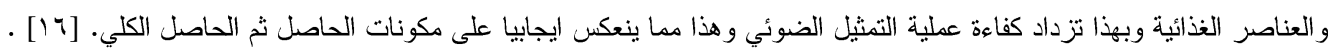


جدول (6) تأثير التراكيب الور اثية و المسافات بين النباتات والتداخل بينهما على صفة حاصل النبات(غم.نبات-1) للأرة الصفراء

\begin{tabular}{|c|c|c|c|c|}
\hline المتوسط & 30 سم & ل25 25م & 20 20سم & التراكيب الوراثية \\
\hline 128.20 & 135.10 & 130.13 & 119.37 & 1 \\
\hline 117.64 & 128.15 & 119.87 & 104.90 & 2 \\
\hline 139.36 & 145.20 & 140.30 & 132.60 & 3 \\
\hline 121.47 & 132.72 & 124.79 & 114.66 & 4 \\
\hline 142.31 & 155.40 & 145.51 & 126.91 & 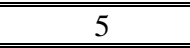 \\
\hline 125.42 & 137.17 & 127.54 & 111.32 & 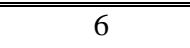 \\
\hline 129.06 & 138.95 & 131.35 & 118.29 & متوسط السلالات \\
\hline 175.93 & 188.60 & 177.66 & 160.30 & $1 \times 2$ \\
\hline 143.07 & 154.59 & 145.65 & 130.74 & $1 \times 3$ \\
\hline 148.79 & 159.31 & 150.69 & 135.82 & $1 \times 4$ \\
\hline 179.73 & 188.40 & 182.03 & 167.53 & $1 \times 5$ \\
\hline 172.40 & 180.09 & 170.49 & 166.41 & $1 \times 6$ \\
\hline 150.10 & 162.47 & 152.30 & 136.97 & $2 \times 3$ \\
\hline 153.49 & 166.19 & 155.47 & 140.49 & $2 \times 4$ \\
\hline 187.13 & 202.10 & 190.56 & 171.53 & $2 \times 5$ \\
\hline 158.86 & 169.74 & 162.43 & 143.94 & $2 \times 6$ \\
\hline 165.95 & 165.34 & 159.69 & 141.92 & $3 \times 4$ \\
\hline 210.87 & 230.87 & 212.44 & 188.77 & $3 \times 5$ \\
\hline 145.92 & 157.33 & 150.70 & 128.93 & $3 \times 6$ \\
\hline 222.17 & 243.65 & 225.81 & 198.73 & $4 \times 5$ \\
\hline 144.30 & 158.35 & 149.53 & 125.91 & $4 \times 6$ \\
\hline \multirow[t]{2}{*}{202.92} & 225.49 & 205.55 & 176.36 & $5 \times 6$ \\
\hline & 174.38 & 160.71 & 137.24 & المتوسط \\
\hline & ئ اخل 12.27 & 17.20 للمسافات & للتر اكيب الور اثية 10.13 & L.S.D \\
\hline
\end{tabular}

يتضح من الجدول (7) وجود فروقا معنوية في التزاكيب المدروسة والمسافات بين النباتات والتداخل بينها لصفة الحاصل الكلي ابي تفوقت السلالة (5) بإعطائها اعلى متوسط للصفة بلغ 7.7 (طن.هـ-') ولم تختلف معنويا عن السلالة (3) التي اعطت حاصل كليا قدره 7.5 (طن.هـ

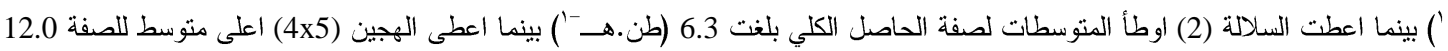
(طن.هـ-') وقد اعطى الهجين (1x3) اوطأ المنوسطات بلغ 7.7 (طن.هـ-') .اما تأثثر المسافات على صفة الحاصل الكلي فكانت معنوية فقد

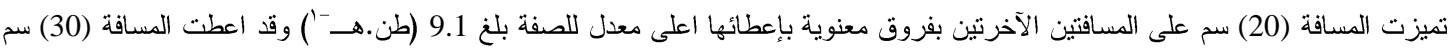

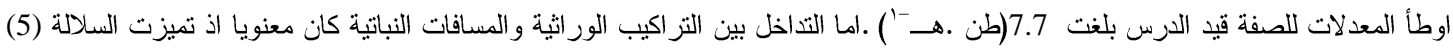

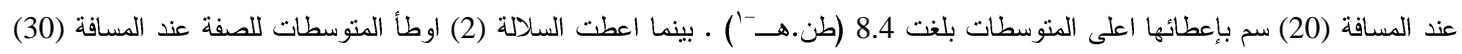
سم بلغت 5.6 (طن.هـ-') اما بالنسبة للهجن فقد تقوق الهجين (4x5) عند المسافة (20) سم معطيا اعلى المتوسطات للصفة المدروسة بلغت

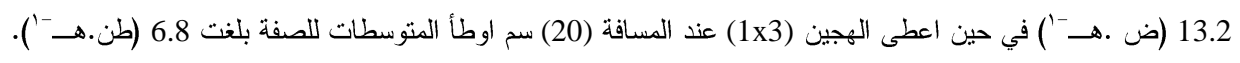

ويعزى زيادة الحاصل الكلي عند تقليل المسافة بين النباتات الى عدم قدرة النبات على الاستفادة من المسافة الزراعية الواسعة بين النباتات في

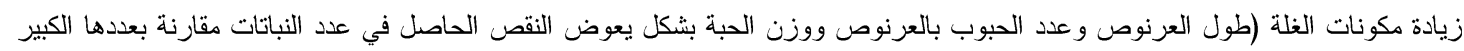

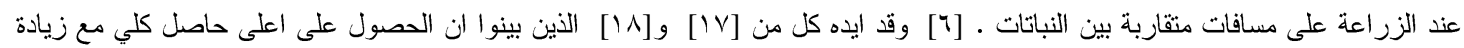
الكثافة النباتية. 
يستتنج من البحث ان زيادة المسافة بين النباتات الى الحد الذي يؤدي الى تقليل المنافسة بين النباتات على الضوء وبالتالي رفع كفاءة عملية

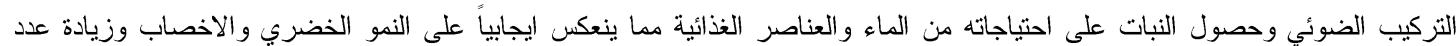
الحبوب ووزن الحبة وبالتالي زيادة الحاصل كمحسلة ودئل نهائية.

جدول (7) تأثير التراكيب الوراثية والمسافات بين النباتات و التداخل بينهما على صفة الحاصل الكلي(طن.هـ-') للأرة الصفراء

\begin{tabular}{|c|c|c|c|c|}
\hline المتوسط & 30 سم & 25 25م & 20 20 & التر اكيب الور اثية \\
\hline 6.9 & 6.0 & 6.9 & 7.9 & $\begin{array}{l}1 \\
\end{array}$ \\
\hline 6.3 & 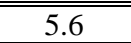 & 6.3 & 6.9 & 2 \\
\hline 7.5 & 6.4 & 7.4 & 8.8 & 3 \\
\hline 6.7 & "5.8 & 6.6 & 7.6 & 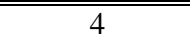 \\
\hline 7.7 & 6.9 & 7.7 & 8.4 & 5 \\
\hline 6.7 & 6.0 & 6.8 & 7.4 & 6 \\
\hline 7.0 & 5.0 & 7.0 & 7.8 & متوسط السلالات \\
\hline 9.5 & 8.3 & 9.4 & 10.6 & $1 \times 2$ \\
\hline 7.7 & 6.8 & 7.7 & 8.7 & $1 \times 3$ \\
\hline 8.0 & 7.0 & 8.0 & 9.0 & $1 \times 4$ \\
\hline 9.8 & 8.7 & 9.7 & 11.1 & $1 \times 5$ \\
\hline 9.3 & 8.0 & 9.0 & 11.0 & $1 \times 6$ \\
\hline 8.1 & 7.2 & 8.1 & 9.1 & $2 \times 3$ \\
\hline 8.3 & 7.3 & 8.2 & 9.3 & $2 \times 4$ \\
\hline 10.1 & 8.9 & 10.1 & 11.4 & $2 \times 5$ \\
\hline 8.6 & 7.5 & 8.6 & 9.5 & $2 \times 6$ \\
\hline 8.4 & 7.3 & 8.5 & 9.4 & $3 \times 4$ \\
\hline 11.3 & 10.2 & 11.3 & 12.5 & $3 \times 5$ \\
\hline 7.8 & 6.9 & 8.0 & 8.5 & $3 \times 6$ \\
\hline 12.0 & 10.8 & 12.0 & 13.2 & $4 \times 5$ \\
\hline 7.7 & 7.0 & 7.9 & 8.3 & $4 \times 6$ \\
\hline $1 . .7$ & 10.0 & 10.9 & 10.9 & $5 \times 6$ \\
\hline 8.500 .39 & 7.770 .14 & 8.581 .81 & 9.149 .24 & المتوسط \\
\hline \multicolumn{2}{|c|}{ للتنداخل 9.} & \multicolumn{2}{|c|}{ للتز اكيب الور اثية ؟. 1.} & L.S.D \\
\hline
\end{tabular}

\section{CONFLICT OF INTERESTS}

\section{There are no conflicts of interest.}

المصادر

[1]الركابي، زهراء حيدر خضير. تاثير الكثافة النباتية والاثيفون في نمو وحاصل الذرة الصفراء (Zea mays L.). رسالة ماجستير، كلية

التقنية المسيب.2016.

[2]F.A.O. http.www.fao.org / site/5671. defult . ancar .Graffing , B. 1956b . "concept of general and apecific combining ability in relation to diallel crossing systems". Aust .J. of Biol .Sci. 9:463-493.2015.

[3][المنظمة العربية للتتمية الزراعية. الكتاب السنوي للاحصاءات الزراعية. المجلد (31)، الخرطوم. السودان. 2011.

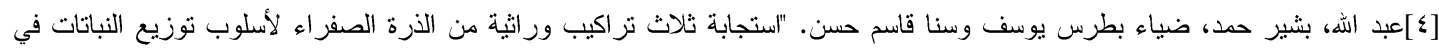
الحقل" . مجلة الانبار للعلوم الزراعية، 8 (4) .2010.

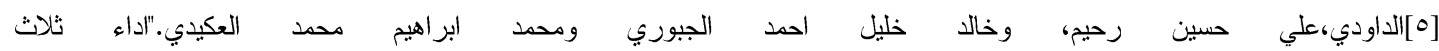
هجن من الذرة الصفر اء للكثافات النباتية و السماد النتروجيني" ـ مجلة ديالى للعلوم الزراعية،7 (1) (1): 133-2015.147.

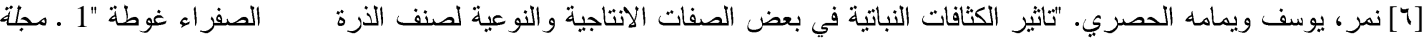

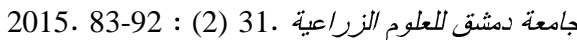

[7] Singh , R.P and R.K Singh."Fcological approaches in weed weed management Nation al Symposium on Conservation and Envi”, October 26-28,2006,301-305.2006.

[1] الساهوكي، مدحت مجيد “بالذرة الصفر اء انتاجها وتحسينها”، وزارة التعليم العالي و البحث العلمي، جامعة بغداد، ص399 ـ1990 


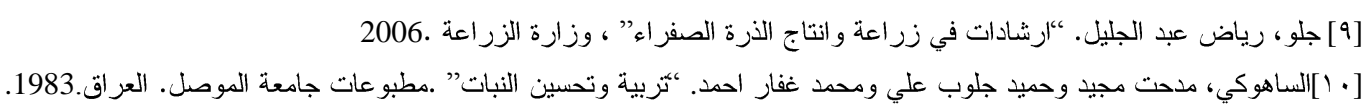

[11] Steel, R.G.D.J.H.Torrie.”principles and procedures in statristi A. Biometrical Approach 2 nd Mc".craw Hil Book co ., NY .USA, pp:485.1980.

[بإكبة، علاء عبد المهدي ابراهيم. تقدير قوة الهجين وبعض المعالم الوراثية للارة الصفراء باستخدام التهجين نصف التبادلي، رسالة

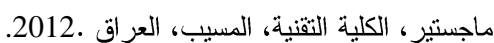

[13]Oktem, A. and A.F. Abdullah. "Effect of nitrogen fresh ear yield protein content and micronutrient concentration sweet corn”. J. Dhilipp .Agric . Sci. 90 (40) : 289-264. 2007.

[14] manuallah, S : M. Mansoor and M.A. Khan."Heteroises studies in diallel cross of maize Sarhad" . J. Agric , 27 (2). 2011

[15] El- Talib, M. A., E. A Elamin , M.M. ElGaziri and Y.F Elmahi ." Combined effect on nitrogen fertilization and soil of $\mathrm{CaCa} 3$ contents on corn performance in Al- mari soil library plant". Nutr. 28 (9) 1619-1632.2005.

[16] Cirilo , A.G., J. Daranelli , M. Balzarini , Androds , F. H. Cantareo . , M. Lugue and S. Pedrol. "Morpho physiological traits associated with maize Crop a deputation to environment differing in nitrogen a viallability". J. Field corp. Res 113 (2) $116-124.2009$.

[17] xue .j. z. liang, G. ma, H , Lu and j . Ren ."population physiological indsces on densing - toler once of menize in different pleut type", ying yong sheng tai yue Bao , 13:55-59.2002.

[18] Sharifi,R.S., R.Taghizadeh.A. F.Sharifi. R., Seved and H. Reza ."Respone of Maiza (Zea mays L.) cultivars of different levels nitrogen fertilizer". S. Food agric environ.7 (4) : 518-521. 2009. 